\title{
Neurofibromatosis Type 1 (von Recklinghausen's disease) in Pregnancy: cesarean delivery outcomes - case report
}

\author{
Brîndușa Lungu*,1, Silvia Baican², Zenovica Bădărău ${ }^{3}$, Zinica Lungu ${ }^{4}$ \\ 1 "Grigore T. Popa" University of Medicine and Pharmacy, lasi, Romania, ${ }^{2}$ Department of Obstetrics \\ and Gynecology of the Emergency Hospital, Pascani, Romania, ${ }^{3}$ Compartment of Neonatology of the \\ Emergency Hospital Pascani, Romania, ${ }^{4}$ Special School, Pascani, Romania
}

\begin{abstract}
Neurofibromatosis type 1 (NF1), also known as von Recklinghausen's disease, is a genetic neurological disorder characterized by cutaneous and plexiform neurofibromas, café-au-lait spots, Lisch nodules, freckling in axillary and inguinal regions, optic gliomas, bone abnormalities and an increased risk of malignancy. It is also reported to be associated with adverse perinatal outcome in pregnant women.

This article presents a case of a pregnant woman with a known NF1 disease since childhood, with a Fourth Ventricle benign tumor surgery, a permanent ventriculoperitoneal shunt and a Right Bundle Branch Block (RBBB). However, this is a case with a normal obstetric outcome, without the aggravation of dermatological lesions of the condition during pregnancy.
\end{abstract}

Keywords: Neurofibromatosis type 1, von Recklinghausen, pregnancy, cesarean delivery

\section{Introduction}

Neurofibromatosis is a hamartomatous disorder of neural crest tissue transmitted in an autosomal dominant manner [1, 2].

Neurofibromatosis type 1 (NF1), also known as von Recklinghausen's disease, is affecting approximately $1 / 3500$ individuals in all ethnic groups. It is characterized by cutaneous and plexiform neurofibromas, caféau-lait spots, Lisch nodules, freckling in axillary and inguinal regions, optic gliomas, bone abnormalities [3], and an increased risk of malignancy [4].

It is also reported to be associated with adverse perinatal outcome in pregnant women [3].

Received: August 2014; Accepted after review: September 2014; Published: September 2014

*Corresponding author: Brîndușa Lungu, "Grigore T. Popa" University of Medicine and Pharmacy, 16 Universitatii St, 700115 lasi, Romania. Email: brindusa.lungu@gmail.com
Most of the current obstetric literature indicates that pregnant women with NF1 have increased risk of complications like spontaneous miscarriage, preterm delivery, preeclampsia, intrauterine growth retardation, stillbirths as well as maternal disease aggravation [5, 6]. However, this is a case with a normal obstetric outcome without the aggravation of dermatological lesions of the condition during pregnancy.

\section{Case report}

A 32-year-old primiparous female (1G1P) was admitted for intense labor pains to the Department of Obstetrics and Gynecology of the Emergency Hospital Pascani, at 37-38 weeks of gestation with asymptomatic cutaneous manifestations of neurofibromatosis on the entire surface of the body: café au lait spots, axillary freckling and neurofibromas (Figures 1-3), along with an extensive congenital plexiform neurofibroma on her left 
breast, extending to the nipple-areolar complex (Figure 4) [7].



Fig. 1. Cutaneous manifestations of NF1 on the posterior chest, right and left upper limbs: neurofibromas and café au lait spots

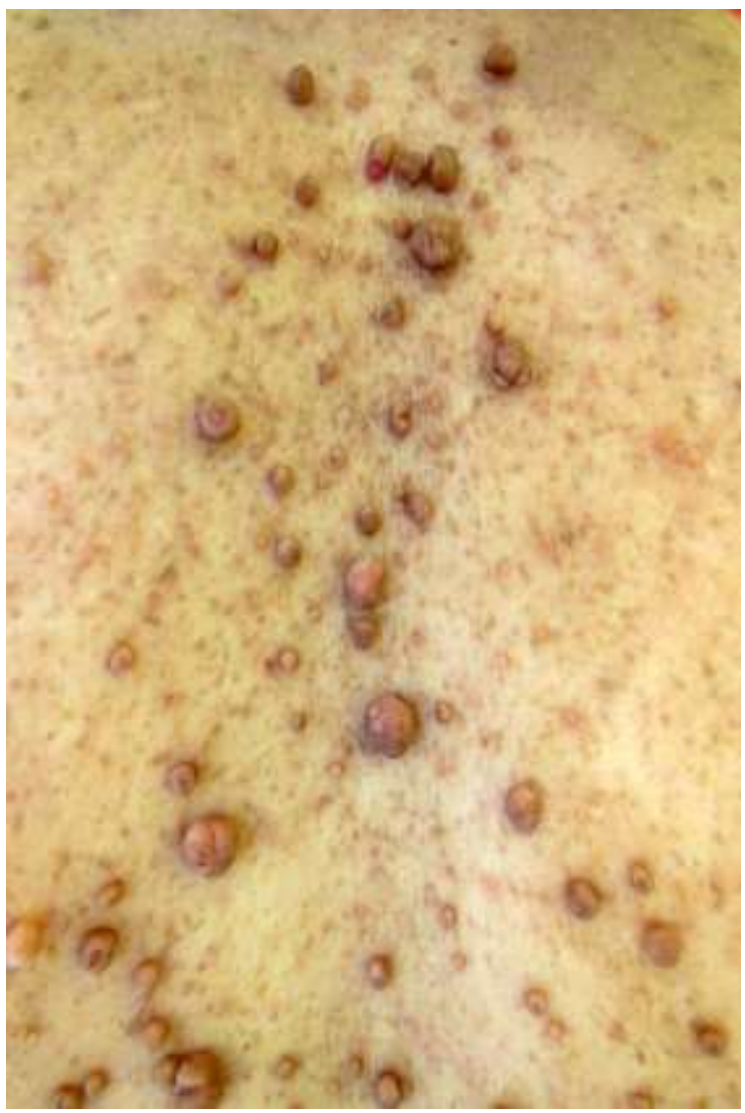

Fig. 2. Neurofibromas on the teguments of the posterior thoracic region

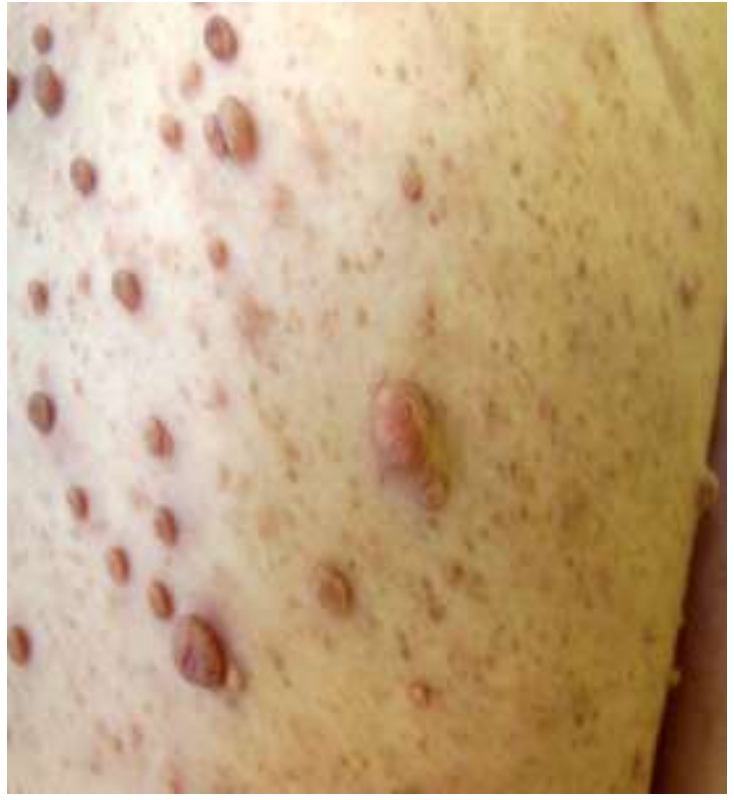

Fig. 3. Neurofibromas and café au lait spots on the teguments of the right lumbar region

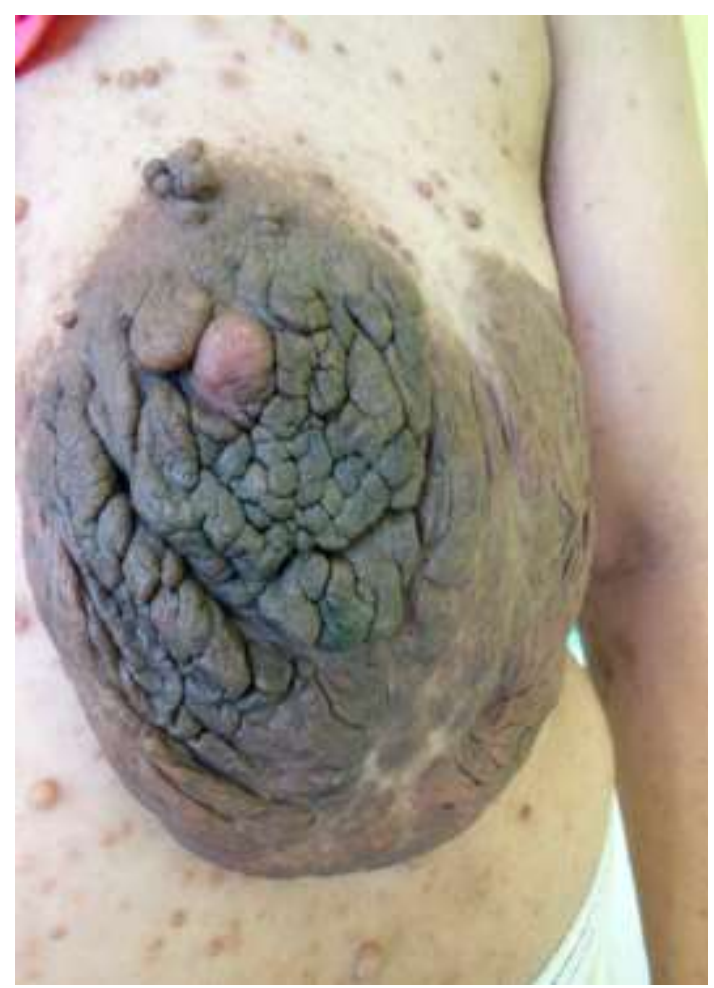

Fig. 4. Extensive congenital plexiform neurofibroma on the left breast, extending to the nipple-areolar complex

The past history of the illness describes that the patient was diagnosed with NF1 disease at the age of 14 , despite the fact that the patient reports that she has had the skin lesions since birth. There was no family history of neurologic or cutaneous disorders. 
At the age of 21 she started experiencing sickness, vomiting, intense headaches, vertigo and she was admitted to the Neurosurgery Department of "Prof. Dr. N. Oblu" Emergency University Hospital, lasi, for further evaluation where she underwent brain surgery for a fourth Ventricle benign tumor. As the patient reports, she then underwent surgery for 14 times for the replacement of the draining system and, 2 years ago, for the placement of a permanent ventriculoperitoneal shunt.

Physical and laboratory examination showed no findings of hypertension or preeclampsia. The EKG revealed a Right Bundle Branch Block (RBBB) and inverted T waves in DII, DIII and aVF, risk factors that necessitated caution when it came to the general anesthesia and the patient had continuously ECG monitoring throughout the operative and perioperative procedures.

Laboratory exams showed a high level of fibrinogen: $678 \mathrm{mg} / \mathrm{dl}$. The ultrasound examination revealed the fetus in cephalic presentation. Doppler ultrasound examination revealed poorly perceptible fetal heartbeat.

The patient reports that part of the neurofibromas on the skin, mostly on the upper limbs, decreased in size during pregnancy.

A segmento-transversal cesarean section was performed due to abnormal Cardiotocogram (CTG) tracings and, after an uncomplicated pregnancy, the patient delivered a male neonate with a tight nuchal cord, weighting $2680 \mathrm{~g}$, with no heartbeating after the $1^{\text {st }}$ minute and with an Apgar score of 6 and 7 at 1 and 5 minutes, respectively.

During the surgery, a second longitudinal section of the uterus was necessary due to the numerous neurofibromas of the uterus that delayed the delivery of the new born. The patient also underwent bilateral tubal ligation at the doctors' advice due to the high risks of complications of the disease. After the surgery, the patient accused intense abdominal pain that required opioid analgesic drugs, Morphine, $2 \mathrm{mg}$.

The infant was admitted in the neonatal intensive care unit where, after 24 hours, he developed necrotizing enterocolitis for which complete recovery 10 days of treatment were necessary. The new born is currently healthy, breast-fed mostly from the mother's right breast (the left breast affected by the neurofibroma has low milk supply), showing, for now, no signs for NF1, but a genetic testing and counseling was also recommended. Both patients, mother and son, were discharged after 15 days of hospital care, with a very good evolution.



Fig.5. ECG of the patient reveals a Right Bundle Branch Block

\section{Discussions}

This article presents a case of a pregnant woman with a known NF1 disease since childhood and with a Fourth Ventricle benign tumor surgery, a permanent ventriculoperitoneal shunt and a RBBB. No major lesions that could compromise pregnancy outcome were detected, thus allowing the pregnancy to continue to term uneventfully [3]. However, this is a case with a normal obstetric outcome, without the aggravation of dermatological lesions of the condition during pregnancy.

Descriptions of individuals purported to have neurofibromatosis have been discovered in manuscripts dating from $1000 \mathrm{AD}$ [8].

However, it was not until 1881 that von Recklinghausen coined the term "neurofibroma" when he observed that this benign tumour arose from the peripheral nerve sheath $[9,10]$. The different forms of neurofibromatosis were separated and delineated in the late $20^{\text {th }}$ century [10-18].

The National Institutes of Health Consensus Development Conference formulated the diagnostic criteria for neurofibromatosis 1 (NF1), underlining the 
pivotal involvement of the skin, bone and the nervous system in the condition [10, 19]. In 1990, the NF1 gene was cloned on chromosome 17q11.2 [10, 20, 21]. Neurofibromin, the gene product, is ubiquitously expressed at high levels in the nervous system and functions as a tumor suppressor [10, 22-24]. Loss of neurofibromin through mutation leads to an increased risk of developing benign and malignant tumours in affected individuals [10].

Neurofibromas mostly start developing at puberty and can increase in size and number during pregnancy $[25,26]$. However, in this case, the patient reported that neurofibromas, mostly of the upper limbs, have decreased in size during pregnancy.

Obstetricians should ensure that pelvic neurofibromas do not impede the delivery [10]. In this case, neurofibromas of the uterus determined a delay in the delivery of the baby and necessitated a second longitudinal section of the uterus.

An increased rate of caesarean section is also reported which could be due to fetal distress, malpresentations and cephalopelvic disproportion due to undiagnosed pelvic neurofibromas and pelvic contractures including cases of kyphoscoliosis affecting the lower spine (sequelae of NF1) $[6,26]$.

Although many affected persons inherit the disorder, between 30 and 50 percent of the new cases arise spontaneously through mutation (change) in an individual's genes. Once this change has taken place, the mutant gene can be passed on to succeeding generations [27, 28].

It is known that NF1 patients may have cognitive problems and behavioral difficulties. Cognitive problems are the commonest neurological complications in NF1 individuals

\section{References}

1. Ricacardi VM. Von Recklinghausen neurofibromatosis. NEJM 1981; 305:1617-1626.

2. Pilmore $\mathrm{H}, \mathrm{Na}$ Nagara $M$, Walker $\mathrm{R}$. Neurofibromatosis and renovascular hypertension presenting in early pregnancy. Nephrol Dial Transplant 1997; 12:187-189

3. Stefanidis K, Solomou E, Lagona E, et al. MRI investigation for neurofibromatosis type 1 and usually present as an IQ in the low average range; severe intellectual deficit with an $\mathrm{IQ}<70$ is rare. Specific learning problems have been observed in $30-60 \%$ of NF1 children [10]. Our patient finished only a professional school, not being able to complete her studies because of the disease and also because of her limited financial condition. She is now retired due to her medical condition.

The newborn requires assessment at birth for possible early complications of NF1 and at least yearly review until the disease status is clarified. If there are no features by the age of 2 years, NF1 is unlikely but one final review at 5 years is advised [10].

As a minimal precaution, all patients with RBBB should have continuous ECG monitoring throughout operative or perioperative procedures which are likely to stress the conducting system of the heart [29, 30]. The presence of BBB is not associated with a high incidence of postoperative cardiac complications. Perioperative mortality is not increased in patients with RBBB [31].

Whatever may be the route of delivery, maintaining an adequate balance of myocardial oxygen supply and demand is the key to the successful outcome [30].

\section{Conclusions}

NF1 is a genetic disorder that has increased risk of complications as well as the aggravation of the maternal disease.

However, this is a case with a normal obstetric outcome, without the aggravation of the dermatological lesions of the condition during pregnancy.

lesions during pregnancy-a case report. Clin Exp Obstet Gynecol 2006; 33(4):246-8.

4. Terzi YK, Oguzkan-Balci S, Anlar B, et al. Reproductive decisions after prenatal diagnosis in neurofibromatosis type 1: importance of genetic counseling. Genet Couns 2009; 20(2):195-202. 
5. Weissman A, Jakobi P, Zaidise I, Drugan A. Neurofibromatosis and pregnancy. An update. J Reprod Med 1993; 38(11):890-96.

6. Sangwan N, Duhan N. Normal Obstetric Outcome in Neurofibromatosis-1 Complicating Pregnancy. JK Science 2008; 10(4):197-198.

7. Bongiorno MR, Doukaki $S$, Aricò $M$. Neurofibromatosis of the nipple-areolar area: a case series. J Med Case Rep 2010; 4:22.

8. Zanca A, Zanca A. Antique illustrations of neurofibromatosis. Int $J$ Dermato 1980; 19(1):55-8.

9. Crump T. Translation of case reports in Ueber die multiplen Fibrome der Haut und ihre Beziehung zu den multiplen Neuromen by F. v. Recklinghausen. Adv Neurol 1981; 29:259-75.

10. Ferner $\mathrm{R}$, Huson $\mathrm{S}$, Thomas $\mathrm{N}$, et al. Guidelines for the diagnosis and management of individuals with neurofibromatosis 1. J Med Genet 2007; 44(2):81-88.

11. Ruggierei M, Huson SM. The clinical and diagnostic implications of mosaicism in the neurofibromatoses. Neurology 2001; 56(11):1433-43.

12. Korf BR, Huson SM. The Phakamatoses. In: Rimoin D, Connor JM, Pyeritz RE, Korf BR, eds. Principles and practice of medical genetics, $5^{\text {th }}$ edn. Edinburgh: Churchill Livingstone 2006; 90(6):924-7.

13. Bandipalliam $P$. Syndrome of early onset colon cancer, haematological malignancy and features of neurofibromatosis in HNPCC families with homozygous mismatch repair gene mutations. Fam Cancer 2005; 4(4):32333.

14. De Luca A, Bottiloo I, Sarkozy A, et al. NF1 gene mutations represent the major molecular event underlying neurofibromatosis-Noonan syndrome. Am J Med Genet 2005; 77(6):1092101.

15. Evans DGR, Moran A, King A, et al. Incidence of vestibular schwannoma and neurofibromatosis 2 in the north west of England over a 10-year period: higher incidence than previously thought. Otol Neurotol 2005; 26(1):93-7.

16. Trofatter J, MacCollin M, Rutter JL, et al. A novel moesin-esrin-radixin-like gene is a candidate for the neurofibromatosis 2 tumours suppressor. Cell 1993; 72(5):791-800.

17. Evans DGR, Huson SM, Donnai D, et al. A clinical study of type 2 neurofibromatosis. $Q J$ Med 1992; 84(304):603-18.

18. MacCollin M, Chiocca EA, Evans DG, et al. Diagnostic criteria for schwannomatosis. Neurology 2005; 64(11):1838-45.
19. ${ }^{* * *}$ Neurofibromatosis. Conference statement. National Institutes of Health Consensus Development Conference. Arch Neurol 1988; 45(5):575-8.

20. Viskochil D, Buchberg AN, Xu G, et al. Deletions and a translocation interrupt a cloned gene at the neurofibromatosis type 1 locus. Cell 1990; 62(1):187-92.

21. Wallace MR, Marchuk DA, Anderson LB, et al. Type 1 neurofibromatosis gene; identification of a larger transcript disrupted in three NF1 patients. Science 1990; 249(4965):181-6.

22. Xu GF, O'Connell P, Viskochil D, et al. The neurofibromatosis type 1 gene encodes a protein related to GAP. Cell 1990; 62(3):599608.

23. Gutmann DH, Wood DL, Collins FS. Identification of the neurofibromatosis 1 gene product. Proc Natl Acad Sci USA 1991; 88(21):9658-62.

24. Daston MM, Scrable $H$, Nordlund $M$, et al. The protein product of the neurofibromatosis type 1 gene is expressed at highest abundance in neurons, Schwann cells and oligodendrocytes. Neuron 1992; 8(3):415-28.

25. Lammert M, Mautner V, Kluwe L. Do hormonal contraceptives stimulate growth of neurofibromas? A survey on 59 NF1 patients. BMC Cancer 2005; 5:16.

26. Dugoff L, Sujansky E. Neurofibromatosis type 1 and pregnancy. Am J Med Genet 1996; 66(1):7-10.

27. National Institute of Neurological Disorders and Stroke-NINDS Neurofibromatosis Information Page

[http://www.ninds.nih.gov/disorders/neurofibro matosis/neurofibromatosis.htm available at 9.09.2014]

28. Hsieh DT. Neurofibromatosis Type 1. Medscape

[http://emedicine.medscape.com/article/117726 6-overview available at 9.09.2014]

29. Pastore JO, Yurchak PM, Janis KM, Murphy JD, Zir LM. The risk of advanced heart block in surgical patients with right bundle branch block and left axis deviation. Circulation 1978; 57:677-680.

30. Salgaonkar S, Chaudhari L. Anaesthetic management of emergency cesarean section in a case of myocardial infarction with left ventricular dysfunction. Indian J Anaesth 2003; 47(4):293-295.

31. Dorman T, Breslow MJ, Pronovost PJ, Rock P, Rosenfeld BA. Bundle-branch block as a risk factor in noncardiac surgery. Arch Intern Med 2000; 160(8):1149-52. 